\title{
Dimethylsulfide gas transfer coefficients from algal blooms in the Southern Ocean
}

\author{
T. G. Bell ${ }^{1,2}$, W. De Bruyn ${ }^{3}$, C. A. Marandino ${ }^{4}$, S. D. Miller ${ }^{5}$, C. S. Law ${ }^{6,7}$, M. J. Smith ${ }^{6}$, and E. S. Saltzman ${ }^{2}$ \\ ${ }^{1}$ Plymouth Marine Laboratory, Prospect Place, The Hoe, Plymouth, PL1 3DH, UK \\ ${ }^{2}$ Department of Earth System Science, University of California, Irvine, CA, USA \\ ${ }^{3}$ School of Earth and Environmental Science, Chapman University, Orange, California, CA, USA \\ ${ }^{4}$ Forschungsbereich Marine Biogeochemie, GEOMAR/Helmholtz-Zentrum für Ozeanforschung Kiel, \\ Düsternbrooker Weg 20, 24105 Kiel, Germany \\ ${ }^{5}$ Atmospheric Sciences Research Center, State University of New York at Albany, NY, USA \\ ${ }^{6}$ National Institute of Water and Atmospheric Research (NIWA), Evans Bay Parade, Kilbirnie Wellington, 6002, New Zealand \\ ${ }^{7}$ Department of Chemistry, University of Otago, Dunedin, New Zealand
}

Correspondence to: T. G. Bell (tbe@pml.ac.uk)

Received: 23 October 2014 - Published in Atmos. Chem. Phys. Discuss.: 17 November 2014

Revised: 19 January 2015 - Accepted: 23 January 2015 - Published: 19 February 2015

\begin{abstract}
Air-sea dimethylsulfide (DMS) fluxes and bulk air-sea gradients were measured over the Southern Ocean in February-March 2012 during the Surface Ocean Aerosol Production (SOAP) study. The cruise encountered three distinct phytoplankton bloom regions, consisting of two blooms with moderate DMS levels, and a high biomass, dinoflagellate-dominated bloom with high seawater DMS levels (> $15 \mathrm{nM})$. Gas transfer coefficients were considerably scattered at wind speeds above $5 \mathrm{~ms}^{-1}$. Bin averaging the data resulted in a linear relationship between wind speed and mean gas transfer velocity consistent with that previously observed. However, the wind-speed-binned gas transfer data distribution at all wind speeds is positively skewed. The flux and seawater DMS distributions were also positively skewed, which suggests that eddy covariance-derived gas transfer velocities are consistently influenced by additional, log-normal noise. A flux footprint analysis was conducted during a transect into the prevailing wind and through elevated DMS levels in the dinoflagellate bloom. Accounting for the tempo$\mathrm{ral} / \mathrm{spatial}$ separation between flux and seawater concentration significantly reduces the scatter in computed transfer velocity. The SOAP gas transfer velocity data show no obvious modification of the gas transfer-wind speed relationship by biological activity or waves. This study highlights the challenges associated with eddy covariance gas transfer measure-
\end{abstract}

ments in biologically active and heterogeneous bloom environments.

\section{Introduction}

Gas exchange across the ocean-atmosphere interface influences the atmospheric abundance of many compounds of importance to climate and air quality. Such compounds include greenhouse gases, aerosol precursors, stratospheric ozonedepleting substances, and a wide range of photochemically reactive volatile organic carbon compounds that influence tropospheric ozone. Estimating the air-sea fluxes of all of these compounds requires knowledge of their distributions in near-surface air and seawater and an understanding of the transport processes controlling gas exchange across the airsea interface. The transport processes are not well understood, in large part because of the paucity of direct air-sea gas flux observations. The parameterization of gas exchange is a significant source of uncertainty in ocean-atmosphere exchange in global models, particularly at high wind speeds (Elliott, 2009).

Gas flux is typically calculated using the concentration gradient across the air-sea interface $(\Delta C)$ and the gas transfer coefficient $(K)$ :

Flux $=K \cdot \Delta C$. 
$K$ represents the inverse of the resistance to gas transfer on both the water and air sides of the interface (i.e., $1 / K=$ $r_{\mathrm{w}}+r_{\mathrm{a}}$ ) and can be expressed in either waterside or airside units (Liss and Slater, 1974). Equation (1) is a very simple expression that belies the complex physical process involving diffusive and turbulent mixing at the boundary between two mediums of very different densities. Wind stress is the predominant forcing for gas transfer, but mixing at the interface is also influenced by buoyancy, wind-wave interactions, wave breaking, surfactants, and bubble generation. The interface is chemically complex owing to the presence of organic films or particles, and, for some gases, the interface may be biologically/photochemically reactive.

Most air-sea gas transfer calculations utilize wind speedbased parameterizations derived from deliberate dual tracer observations (Ho et al., 2011; Nightingale et al., 2000), sometimes scaled to agree with the long-term global average oceanic uptake of ${ }^{14} \mathrm{CO}_{2}$ (Sweeney et al., 2007). The dual tracer technique is a waterside method that requires data averaging over periods of hours to days, thus averaging over significant changes in conditions. Eddy covariance is a direct flux measurement carried out on the air side of the interface. In conjunction with measurements of the air-sea concentration difference, eddy covariance studies can determine the gas transfer coefficient, $K$, on short timescales $(10 \mathrm{~min}-1 \mathrm{~h})$. This provides a capability to assess variability in $K$ due to the influence of rapid changes in near-surface processes (e.g., wind-wave interactions, bubbles, surfactants). Eddy covariance requires high-frequency sensors, and flux studies to date have been carried out on only a few compounds: dimethylsulfide (DMS), $\mathrm{CO}_{2}$, methanol, acetaldehyde, acetone, ozone, carbon monoxide, dinitrogen pentoxide, chloro(oxo)azane oxide and glyoxal (Huebert et al., 2004; McGillis et al., 2001; Yang et al., 2013; Kim et al., 2014; Blomquist et al., 2012; Bariteau et al., 2010; Marandino et al., 2005; Coburn et al., 2014).

DMS air-sea transfer resistance is predominantly on the water side, a characteristic it shares with $\mathrm{CO}_{2}$. DMS is moderately soluble and weakly influenced by bubble-mediated gas transfer, in contrast to $\mathrm{CO}_{2}$, which is sparingly soluble and strongly influenced by bubble-mediated gas transfer. This makes DMS a useful tracer for waterside-controlled, interfacial gas transfer. Measurements of gas exchange using insoluble gases have suggested that the relationship between $K$ and wind speed is non-linear (Nightingale et al., 2000; Sweeney et al., 2007; Miller et al., 2010; Ho et al., 2011). In contrast, the majority of DMS eddy covariance data suggests a linear relationship between $K$ and wind speed (Yang et al., 2011). Blomquist et al. (2006) suggest that the differences in functional form of these relationships may be due to the disproportionate influence of bubbles upon the flux of insoluble gases (Woolf, 1997).

Physical process models have made significant progress in parameterizing gas exchange with input terms that include but are not limited to wind speed. However, these models are still in development and are capable of substantially different estimates of $K$, depending on how non-wind-speed terms such as wind-wave dynamics are applied in the model (Fairall et al., 2011; Soloviev, 2007). Bell et al. (2013) recently demonstrated that some of the scatter in eddy covariance measurements may be explained by spatial/temporal differences in wind-wave interaction, although the role of surfactants cannot be ruled out. Gas exchange measurements in an artificial surfactant patch (Salter et al., 2011) and in laboratory studies using natural surfactants (Frew et al., 1990) have demonstrated marked suppression of gas transfer. Additional eddy covariance gas exchange observations are required to improve these gas exchange models. Eddy covariance DMS flux measurements have been made in the Atlantic Ocean (Bell et al., 2013; Marandino et al., 2008; Salter et al., 2011; Blomquist et al., 2006) and Pacific Ocean (Marandino et al., 2007, 2009; Yang et al., 2009), with three of these studies at high northern latitudes. Only one previous study has been performed in the Southern Ocean (Yang et al., 2011).

The Southern Ocean has a unique wind and wave environment: minimal land mass in the Southern Hemisphere leads to strong, consistent winds and waves with a long fetch. The duration of the wind speed event rather than the wind fetch is the most important factor influencing the waves (Smith et al., 2011). This region is very important in determining the global uptake of atmospheric $\mathrm{CO}_{2}$ by the ocean (Sabine et al., 2004) and the supply of DMS as a source of atmospheric sulfate aerosol (Lana et al., 2011). This paper presents data collected in the Southern Ocean summer (February-March 2012) as part of the New Zealand Surface Ocean Aerosol Production (SOAP) cruise (Fig. 1). During the cruise, a variety of oceanic, atmospheric and flux measurements were collected. The cruise targeted regions of extremely high biological activity (blooms of dinoflagellates and coccolithophores) and encountered a number of atmospheric frontal events leading to winds in excess of $11 \mathrm{~m} \mathrm{~s}^{-1}$.

\section{Methods}

\subsection{Mast-mounted instrumentation and data acquisition setup}

The eddy covariance setup was mounted on the bow mast of the R/V Tangaroa, $12.6 \mathrm{~m}$ above the sea surface. Three-dimensional winds and sonic temperature (Campbell CSAT3) and platform angular rates and accelerations (Systron Donner Motion Pak II) were measured on the mast and co-located with the air sampling inlets for DMS. Air was drawn through the sampling inlets at 90 SLPM under fully turbulent flow conditions $(R e>10000)$. Analog signals from all of these instruments were filtered at 15 and then logged at $50 \mathrm{~Hz}$ (National Instruments SCXI-1143). The ship's compass and GPS systems were digitally logged at $1 \mathrm{~Hz}$. The mast configuration was similar to that used dur- 


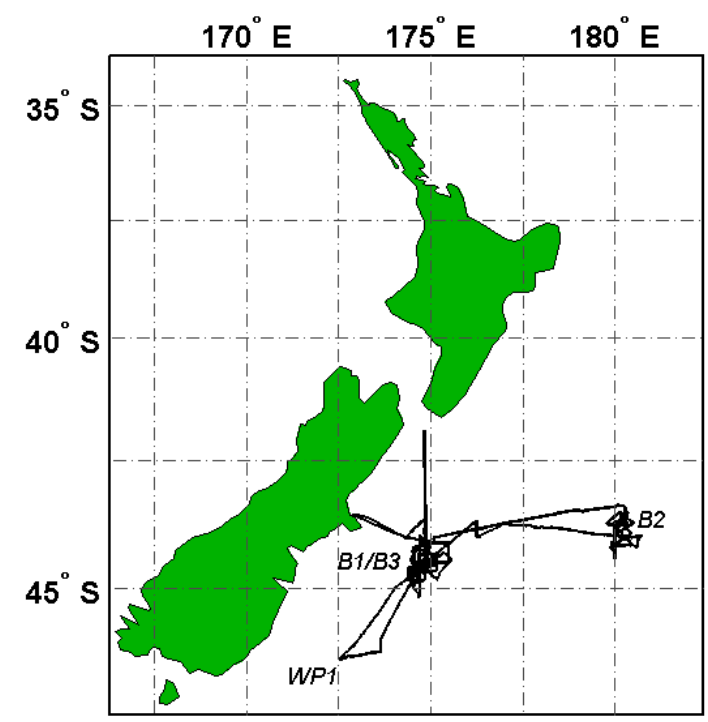

Figure 1. Cruise track during the SOAP study, which began and finished in Wellington, New Zealand. The phytoplankton blooms (B1-3) and waypoint 1 (WP1) locations are identified.

ing the Knorr_11 North Atlantic cruise (Bell et al., 2013), with the following two changes.

1. An air sampling inlet with integral ports for standard delivery was fabricated from a solid block of PTFE. The design minimized regions of dead space that might attenuate high-frequency fluctuations and result in loss of flux signal.

2. A shorter length of $3 / 8^{\prime \prime}$ ID Teflon tubing was used between the mast and the container van. A $19 \mathrm{~m}$ inlet was used during SOAP in contrast to the $28 \mathrm{~m}$ inlet used during Knorr_11 (Bell et al., 2013).

\subsection{Atmospheric and seawater DMS}

DMS was measured in air and in gas equilibrated with seawater using two atmospheric pressure chemical ionization mass spectrometers (Bell et al., 2013). In both instruments, a heated $\left(400^{\circ} \mathrm{C}\right)$ radioactive nickel foil $(\mathrm{Ni}-63)$ generates protons that associate with water molecule clusters in the sample stream. Protonated water vapor $\left(\mathrm{H}_{3} \mathrm{O}^{+}\right)$undergoes a charge transfer reaction to form protonated DMS ions $(m / z=63)$ that are then quadrupole mass filtered and counted. Trideuterated DMS (d3-DMS, $m / z=66$ ) was used as an internal standard for both instruments.

Atmospheric measurements were made with the University of California, Irvine (UCI) mesoCIMS instrument (Bell et al., 2013). A gaseous d3-DMS standard was introduced to the atmospheric sample stream at the air inlet via a three-way valve mounted at the base of the bow mast. The gas standard was diverted to waste every $4 \mathrm{~h}$ and the response of the $\mathrm{d} 3$ DMS signal recorded as a measure of the inlet tubing impact on signal delay and frequency loss. Air from the bow mast was sub-sampled at approximately $1 \mathrm{~L} \mathrm{~min}^{-1}$ and DMS levels were calculated as follows:

$\mathrm{DMS}_{\mathrm{a}}=\frac{S_{63}}{S_{66}} \cdot \frac{F_{\mathrm{Std}}}{F_{\text {Total }}} \cdot C_{\text {Tank }}$,

where $S_{63}$ and $S_{66}$ represent blank-corrected signals from DMS and d3-DMS, respectively $(\mathrm{Hz}), F_{\text {Std }}$ and $F_{\text {Total }}$ are the gas flow rates of the d3-DMS standard and the inlet air $\left(\mathrm{L} \mathrm{min}^{-1}\right)$, and $C_{\text {Tank }}$ is the gas standard mixing ratio.

Seawater measurements were made with a smaller instrument (UCI miniCIMS), which utilizes a modified residual gas analyzer as the mass filter and ion detector (Stanford Research Systems RGA-200; Saltzman et al., 2009). Aqueous d3-DMS standard was delivered by a syringe pump (NewEra NE300) to the ship's underway seawater supply upstream of the equilibrator (see Bell et al., 2013, for details). The natural DMS and the d3-DMS standard are both transported across the membrane and the DMS concentration in seawater in the equilibrator is then calculated as follows:

$\mathrm{DMS}_{\mathrm{SW}}=\frac{\operatorname{Sig}_{63}}{\operatorname{Sig}_{66}} \cdot \frac{F_{\mathrm{Syr}}}{F_{\mathrm{sw}}} \cdot C_{\mathrm{Std}}$

$\mathrm{Sig}_{63}$ and $\mathrm{Sig}_{66}$ represent the average blank-corrected ion currents $(\mathrm{pA})$ of protonated DMS $(\mathrm{m} / z=63)$ and d3-DMS $(m / z=66)$, respectively, $C_{\mathrm{Std}}$ is the concentration of d3DMS liquid standard (nM), $F_{\text {Syr }}$ is the syringe pump flow rate $\left(\mathrm{L} \mathrm{min}^{-1}\right)$, and $F_{\mathrm{sw}}$ is the seawater flow rate $\left(\mathrm{L} \mathrm{min}^{-1}\right)$. Seawater concentrations were averaged at 1 min intervals for the entire SOAP data set. Lag correlation analysis between the ship surface seawater temperature and equilibrator temperature records identified that a 3-4 min adjustment in the $\mathrm{DMS}_{\mathrm{sw}}$ was required to account for the delay between water entering the seawater intake beneath the hull of the ship and it reaching the miniCIMS equilibrator.

We compared our seawater measurements with discrete samples collected and analyzed by the NIWA team using sulfur chemiluminescence detection (SCD). The NIWA discrete analyses were performed on water collected from both the underway supply and from CTD Niskin bottles fired in the near surface $(<10 \mathrm{~m})$. The analytical techniques (SCD and miniCIMS) typically agreed well and these results will be discussed elsewhere. Throughout the cruise, data from the underway and CTD bottles were in good agreement (Fig. 2), with the exception of day of year (DOY) 54-55, when the ship's underway supply became significantly contaminated. The contamination was biological and resulted in DMS levels at least twofold higher than from a Niskin bottle fired at the same depth. Flushing and soaking the underway lines in a biologically active cleaning solution $\left(\right.$ Gamazyme $^{\mathrm{TM}}$ ) and cleaning the equilibrator with dilute $(10 \%)$ hydrochloric acid resolved the problem. The data from DOY 54-55 have been excluded from our analysis. 


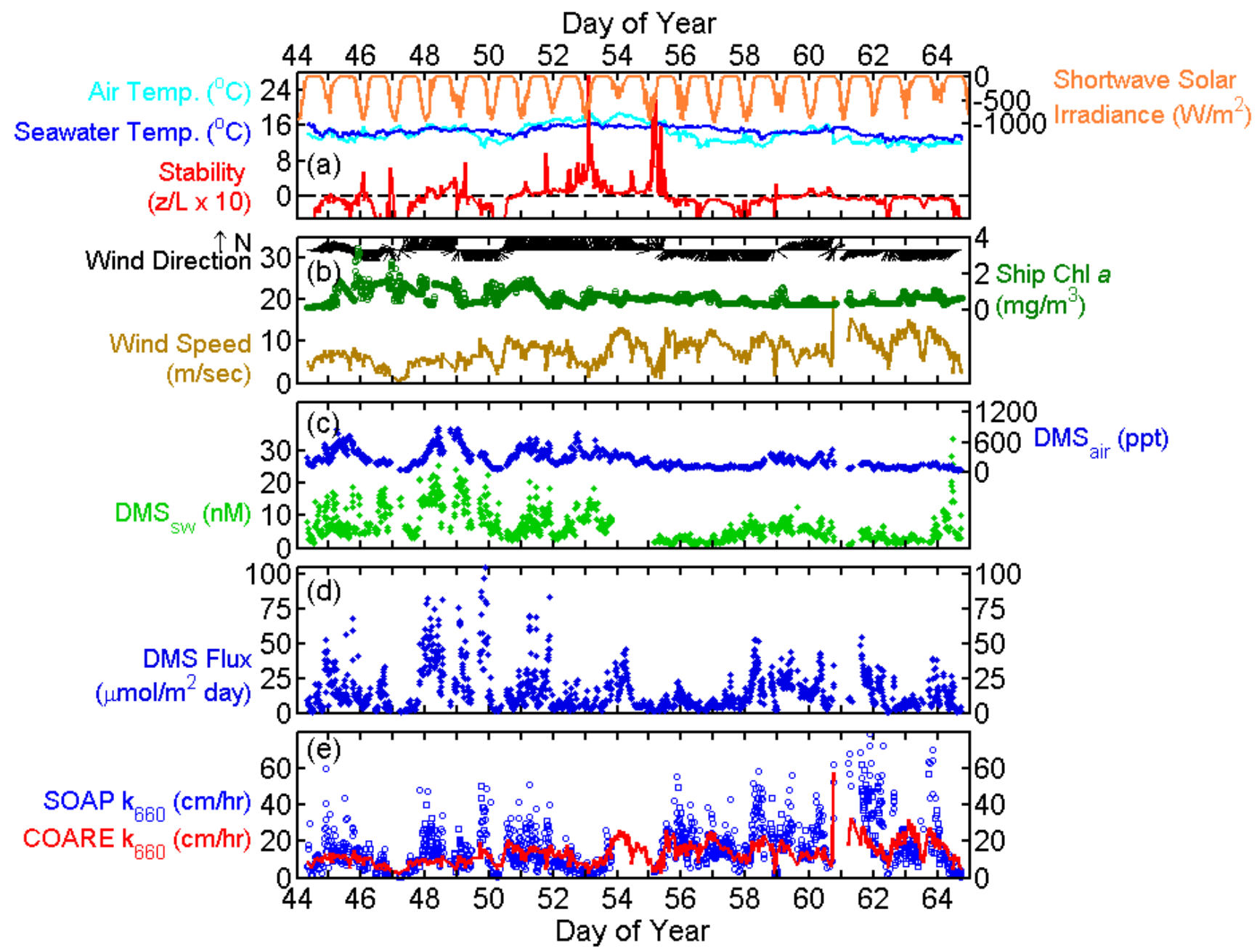

Figure 2. Time series data (10 min averages) from the SOAP cruise. The dashed black line in (a) indicates neutral atmospheric stability $(z / L=0)$. SOAP $k_{660}$ data (e) are divided into on station (squares, ship speed $<1.5 \mathrm{~m} \mathrm{~s}^{-1}$ ) and off station (circles, ship speed $\geq 1.5 \mathrm{~m} \mathrm{~s}{ }^{-1}$ ).

\subsection{DMS flux calculation: eddy covariance data processing and quality control}

Air-sea flux calculation involved the same procedure detailed in Bell et al. (2013). Apparent winds were corrected for ship motion according to the procedures of Edson et al. (1998) and Miller et al. (2008). Relative wind speed was adjusted to correct for air-flow distortion according to the wind direction-dependent correction presented by Smith et al. (2011), which uses the computational fluid dynamics Gerris model (Popinet et al., 2004). 10 min flux intervals with a mean relative wind direction within $\pm 90^{\circ}$ (where winds onto the bow $=0^{\circ}$ ) were retained for subsequent data analysis. The DMS signal was adjusted relative to the wind signals to account for the timing delay due to the inlet tubing. The delay was estimated to be $1.9 \mathrm{~s}$ from the periodic firing of a threeway valve on the bow mast. An equivalent delay estimate was ascertained by optimization of the cross-correlation between DMS and vertical wind. Flux intervals were computed from the co-variation in fluctuations in vertical winds $\left(w^{\prime}\right)$ and DMS $\left(c^{\prime}\right)$ flux. The internal d3-DMS standard exhibited negligible covariance with vertical wind, confirming that no density correction due to water vapor or temperature fluctuations (i.e., Webb correction) was required for our DMS fluxes.

Cospectral analysis objectively removed intervals with large low-frequency fluctuations, and the criteria for elimination are defined in Bell et al. (2013). This process reduced scatter in the data without introducing an obvious bias. Highfrequency flux loss in the inlet tubing was estimated by modeling a filter based on the d3-DMS signal attenuation when the bow mast valve was switched. The inverse filter was then applied to wind speed binned DMS cospectra. This enabled an estimate of the necessary wind-speed-dependent highfrequency loss correction (flux gain $=0.004 U_{10 n}+1.012$ ). 


\subsection{DMS gas transfer velocity calculation}

Gas transfer velocities were calculated following

$K_{\mathrm{DMS}}=\frac{F_{\mathrm{DMS}}}{\Delta C}=\frac{F_{\mathrm{DMS}}}{\mathrm{DMS}_{\mathrm{sw}}-\left(\mathrm{DMS}_{\mathrm{air}} / H_{\mathrm{DMS}}\right)}$,

where $F_{\text {DMS }}$ is the measured DMS air-sea flux $\left(\mathrm{mol} \mathrm{m} \mathrm{m}^{-2} \mathrm{~s}^{-1}\right), \mathrm{DMS}_{\mathrm{sw}}$ is the seawater DMS level $\left(\mathrm{mol} \mathrm{m}^{-3}\right), \mathrm{DMS}_{\text {air }}$ is the atmospheric DMS partial pressure (atm), and $H_{\mathrm{DMS}}$ is the temperature-dependent DMS solubility in seawater (atm $\mathrm{m}^{3} \mathrm{~mol}^{-1}$; Dacey et al., 1984). $K_{\text {DMS }}$ values were calculated from the cruise data using $10 \mathrm{~min}$ averages.

The water side only gas transfer coefficient, $k_{\mathrm{w}}$, was obtained from the expression

$k_{\mathrm{w}}=\left[\frac{1}{K_{\mathrm{DMS}}}-\frac{1}{\alpha \cdot k_{\mathrm{a}}}\right]^{-1}$,

where $K_{\text {DMS }}$ is the total DMS gas transfer coefficient, $\alpha$ is the dimensionless Henry's law constant for DMS, and $k_{\mathrm{a}}$ is the air-side gas transfer coefficient. In situ $k_{\mathrm{a}}$ values were obtained from NOAA COARE driven by in situ measurements of wind speed, atmospheric pressure, humidity, irradiance and air and seawater temperature. The relative influence of $k_{\mathrm{a}}$ upon our estimates of $k_{\mathrm{w}}$ was greater when measured $K_{\text {DMS }}$ was high (Fig. A, in the Supplement). This has little impact upon our data, as the average (mean) difference between $k_{\mathrm{W}}$ and $K_{\mathrm{DMS}}$ was $7 \%$ and showed no wind speed dependence (Fig. B in the Supplement). In order to compare our results with various other gas transfer parameterizations, $k_{\mathrm{w}}$ was then normalized to a Schmidt number of $660\left(\mathrm{CO}_{2}\right.$ at $\left.25^{\circ} \mathrm{C}\right)$ :

$k_{660}=k_{\mathrm{w}} \cdot\left(\frac{660}{S c_{\mathrm{DMS}}}\right)^{-1 / 2}$

where $S c_{\text {DMS }}$ is calculated using the ship's seawater temperature recorded at the bow and Eq. (15) in Saltzman et al. (1993).

\section{Results}

\subsection{Cruise track, meteorological, and oceanographic setting}

The SOAP cruise sampling strategy was to identify phytoplankton blooms using ocean color imagery and then use underway sensors (e.g., chlorophyll $a$ fluorescence, DMS) to map out the in situ spatial distribution. Three blooms were identified and sampled: B1, B2 and B3 (Fig. 1). B1 was an intense dinoflagellate-dominated bloom at approx. $44.5^{\circ} \mathrm{S}$, $174.7^{\circ} \mathrm{E}$ (DOY 45.9-49.8) with extremely high levels of seawater DMS $(16.8 \pm 1.5 \mathrm{nM})$. After B1, the ship headed southwest to a waypoint (WP1) at approx. $46.3^{\circ} \mathrm{S}, 172.5^{\circ} \mathrm{E}$
(DOY 50.5). The waters at WP1 contained moderate DMS signals $(3.8 \pm 0.4 \mathrm{nM})$ and weakening fluorescence $(0.83 \pm$ $0.38 \mathrm{mg} \mathrm{m}^{-3}$ ), so minimal time was spent at this location. The return transect into B1 from WP1 is discussed in detail in Sect. 3.3. The second bloom (B2) was a coccolithophoredominated bloom at approx. 43.6 $6^{\circ} \mathrm{S}, 180.2^{\circ} \mathrm{E}$ (DOY 52.9$56.1)$ that had stronger DMS signals $(9.1 \pm 2.9 \mathrm{nM})$ and fluorescence $\left(0.99 \pm 0.35 \mathrm{mg} \mathrm{m}^{-3}\right)$. After sampling B2, the B1 location was revisited and a new bloom (B3) was identified with a mixed population of coccolithophores, flagellates and dinoflagellates (DOY 57.9-60.5). B3 DMS levels $(5.9 \pm 1.5 \mathrm{nM})$ were substantially lower than in B1.

The time series plot in Fig. 2 describes the oceanographic and meteorological variability throughout the cruise. Surface ocean temperatures (SSTs) were consistent at $14.7 \pm 1.0^{\circ} \mathrm{C}$, while atmospheric temperature fluctuated just above and below the SST. Weather systems from the north brought relatively warm air and systems from the south brought cooler air. For example, the atmospheric front on DOY 55 from the south caused air temperatures to drop from approximately 18 to $12^{\circ} \mathrm{C}$ (Fig. 2a). Frontal systems passed over the ship regularly throughout the cruise and the final system (DOY 61.6-64) brought intense winds from the north. During SOAP, the horizontal wind speeds predominantly ranged from 1 to $15 \mathrm{~m} \mathrm{~s}^{-1}$. The atmospheric boundary layer was stable $(z / L>0.05)$ for approximately $25 \%$ of the cruise (Fig. 2a). Yang et al. (2011) suggest that a stable boundary layer leads to greater scatter and a potentially negative bias in $k_{660}$ vs. wind speed plots. Our data do not suggest increased scatter or any bias during stable periods (Fig. C in the Supplement), and we have not filtered the SOAP $k_{660}$ data on this basis.

Oceanic and atmospheric DMS levels were extremely high during the first half of the cruise (DOY 44-54; Fig. 2c). The majority of this period was spent in and around B1 waters, with elevated seawater DMS $(>10 \mathrm{nM})$ and atmospheric DMS (> 600 ppt). Oceanic DMS was always at least an order of magnitude greater than atmospheric DMS, meaning that the air-sea concentration gradient was effectively controlled by $\mathrm{DMS}_{\mathrm{sw}}$. The second half of the cruise (DOY 55-65) encountered less productive blooms with lower seawater DMS levels. The reduction in oceanic DMS was mirrored by lower atmospheric DMS levels (151 \pm 73 ppt, DOY 55-65).

10 min average DMS fluxes $\left(F_{\mathrm{DMS}}\right)$ measured by eddy covariance are plotted in Fig. 2. $F_{\text {DMS }}$ reflected the seawater DMS levels, with three notable peaks while inside B1 waters $\left(>60 \mu \mathrm{mol} \mathrm{m}{ }^{-2} \mathrm{day}^{-1}\right.$, DOY 48-50). $F_{\text {DMS }}$ was generally lower during the second half of the cruise $(13 \pm$ $10 \mu \mathrm{mol} \mathrm{m}^{-2}$ day $^{-1}$, DOY 55-65), but elevated fluxes were still observed due to increased horizontal wind speeds (e.g., approx. $45 \mu \mathrm{mol} \mathrm{m}{ }^{-2}$ day $^{-1}$ on DOY 61.6). SOAP gas transfer coefficients were calculated at $10 \mathrm{~min}$ intervals (Fig. 2e) following Eqs. (1)-(6) using measurements of $F_{\text {DMS }}$, oceanic and atmospheric DMS levels and SST. During some periods of constant wind speed, the NOAA COARE (v3.1) estimates 

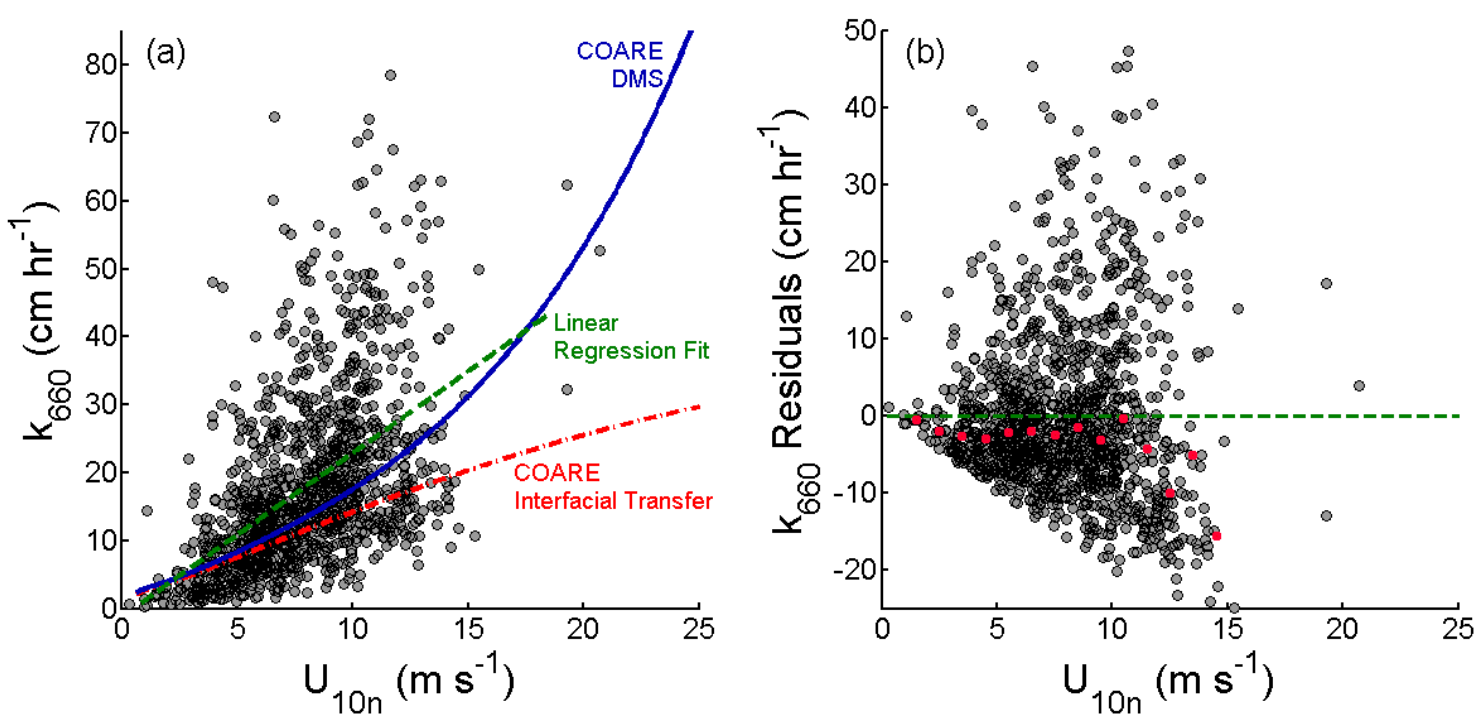

Figure 3. (a) 10 min average DMS gas transfer coefficients vs. mean horizontal wind speed during the SOAP cruise, expressed as $k_{660}$ and $U_{10 n}$ (see Methods). For reference, the NOAA COARE model output for DMS is plotted, calculated using average SOAP input parameters and the turbulent/molecular coefficient, $A=1.6$, and the bubble-mediated coefficient, $B=1.8$. The red dashed line is interfacial transfer velocity only. The blue solid line includes the bubble contribution to gas transfer. The green dashed line is the least squares linear regression fit to the SOAP $10 \mathrm{~min}$ averaged data $\left(k_{660}=2.31 U_{10 n}-1.51\right)$. (b) Residual values from the least squares linear regression fit in (a). The green dashed line is exact agreement with linear regression model. Red squares are the median residual within each $1 \mathrm{~m} \mathrm{~s}^{-1}$ wind speed bin. Negative deviation of the median residuals from the linear regression demonstrates the positive skew in $k_{660}$.

are close to the observed $k_{660}$ values (e.g., DOY 51). However, at various times during the cruise, the NOAA COARE estimates exhibit significant divergence from the observed $k_{660}$ values. The difference was sometimes positive, as on DOY 48, and sometimes negative, as on DOY 53. These divergences are not random scatter about the COARE prediction and suggest that unaccounted-for processes are influencing our measurements of gas transfer.

\subsection{Wind speed dependence of gas transfer coefficients}

The SOAP gas transfer coefficients exhibit a positive correlation with wind speed (Spearman's $\rho=0.57, p<0.01$, $n=1327$; Fig. 3a). A linear least squares fit to the data gives $k_{660}=2.31 \pm 0.11 U_{10 n}-1.51 \pm 0.97$ with an adjusted $R^{2}=$ 0.25 . As with previous shipboard eddy covariance DMS studies, using a second-order polynomial does not improve the fit to the data (adjusted $R^{2}=0.25$ ). The linear model is not well suited for this data set, because the residuals are not normally distributed (Fig. 3b). The frequency distribution of the SOAP $k_{660}$ measurements exhibits positive skewness at all wind speeds (Fig. D in the Supplement). The skew in the SOAP $k_{660}$ data appears to originate in the frequency distribution of seawater DMS. Surface ocean DMS distributions are typically characterized by positive skew, and this is evident in the global surface ocean DMS database (Lana et al., 2011).

It is not surprising to see skewed distributions in the SOAP data, as the cruise encountered strong, non-linear gradients in biological activity. There is no skewness in the distribution of winds within each wind speed bin. Skewness in the seawater DMS distribution should propagate into the DMS flux distribution simply because air-sea flux is proportional to air-sea concentration gradient, which is controlled in turn by seawater DMS levels (Figs. E and F in the Supplement). If $F_{\mathrm{DMS}}$ and $\Delta C$ are highly correlated, then the variance in $k_{660}$ should be considerably less than that in either parameter and would exhibit less skew. This is not the case: $k_{660}$ exhibits a similar skew to $F_{\mathrm{DMS}}$ and $\Delta C$. For example, the correlation coefficient between DMS flux and seawater concentration in the 13-14 $\mathrm{m} \mathrm{s}^{-1}$ wind speed bin (Spearman's $\rho=0.45, p<0.01, n=47$ ) is considerably lower than expected. Decorrelation of DMS flux and seawater concentration is likely due to mismatches between seawater DMS levels measured aboard ship and those in the actual footprint of the flux. Misalignment between seawater DMS levels and the flux footprint is virtually unavoidable in a region of strong spatial heterogeneity, where wind direction and ship track are never perfectly aligned.

As a result of the frequency distribution observations in the SOAP data set, we reexamined data from a recent North Atlantic cruise (Bell et al., 2013; Figs. E-G in the Supplement). The frequency distributions of $k_{660}, F_{\mathrm{DMS}}$ and $\mathrm{DMS}_{\mathrm{sw}}$ exhibit a similar positive skewness to that in the SOAP data set. In order to represent the central tendency of the $k_{660}$ data better and to assess the relationship with wind speed, geometric means were computed for $1 \mathrm{~m} \mathrm{~s}^{-1}$ wind speed 
bins (Fig. 4). Geometric binned $k_{660}$ data from both cruises are lower than the arithmetic binned data. The binned $k_{660}$ SOAP data demonstrate a shallower slope using the geometric means.

The SOAP $k_{660}$ bin average data (Fig. 5) exhibit a linear relationship with wind speed for low and intermediate winds, as found in previous DMS flux studies (e.g., Huebert et al., 2010; Yang et al., 2011; Marandino et al., 2007, 2009). For wind speeds up to $14 \mathrm{~m} \mathrm{~s}^{-1}$, the binned geometric mean SOAP data yield a linear regression equation of $k_{660}=2.07 U_{10 n}-2.42$, which is slightly shallower than that obtained from a compilation of previously published DMS gas transfer measurements $\left(k_{660}=2.6 U_{10 n}-5.7\right.$; GoddijnMurphy et al., 2012). In the higher wind speed bins (above $10 \mathrm{~m} \mathrm{~s}^{-1}$ ), the relationship between $k_{660}$ and wind appears to weaken. A weaker relationship between $k_{660}$ and wind speed at high wind speeds was also observed in the North Atlantic (Bell et al., 2013). In both cruises, there are limited data at wind speeds above $10 \mathrm{~m} \mathrm{~s}^{-1}$, so this phenomenon should be viewed with caution. Bell et al. (2013) suggested that the effect could be due to suppression of near-surface waterside turbulence due to wind-wave interactions (Soloviev et al., 2007; Donelan et al., 2010).

The SOAP study did not include direct measurements of wave properties or surfactants. Significant wave height was estimated using satellite reanalysis products from ECMWF and NCEP, which agreed well (Spearman's $\rho=$ $0.91, p<0.01, n=2876$ ). Significant wave height exceeded $4.5 \mathrm{~m}$ during SOAP. There is no obvious relationship between significant wave height and the scatter in the relationship between gas transfer and horizontal wind speed during SOAP (Fig. $J$ in the Supplement). In situ fluorescence was used as an indicator of biological activity during SOAP. Fluorescence sensors were located in seawater continuously pumped through the ship from the near-surface intake beneath the hull. The variability in the gas transfer velocity data is not explained by surface ocean fluorescence (Fig. $\mathrm{K}$ in the Supplement). Note that fluorescence is not necessarily a reliable indicator of surfactant concentrations. The relative importance of waves and/or surfactants in air-sea gas exchange remains unclear and requires dedicated measurements to be made concurrent with direct assessments of gas exchange by eddy covariance.

\subsection{Uncertainties in $K$ introduced by flux footprint and seawater DMS heterogeneity}

As discussed above, spatial heterogeneity of seawater DMS can introduce uncertainty in gas transfer coefficients derived from eddy covariance studies. It is logistically challenging to quantify footprint effects from a single ship, and it has not been done on prior studies. On the SOAP cruise, the fortuitous alignment of winds and ship track downwind of the dinoflagellate-dominated bloom (B1) provided a unique op-

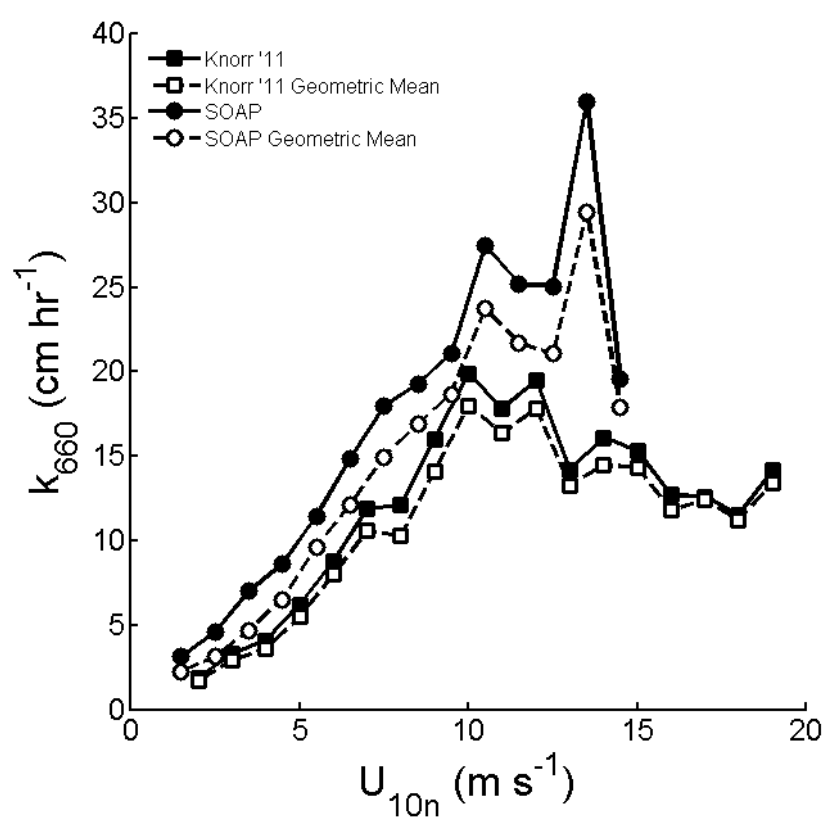

Figure 4. Bin average gas transfer coefficients for this study (SOAP) and the data collected in the North Atlantic (Knorr '11). Mean values were calculated for $1 \mathrm{~m} \mathrm{~s}^{-1} U_{10 n}$ bins using arithmetic (solid lines, filled symbols) and geometric (dashed lines, open symbols) approaches.

portunity to quantify the length scale associated with the flux footprint.

The SOAP cruise spent approximately 5 days mapping out the spatial extent of B1 waters, then transited out of the bloom to WP1 about $150 \mathrm{~km}$ to the southwest. The ship then steamed back into and across B1 at a ship speed of $5.1 \pm 0.7 \mathrm{~m} \mathrm{~s}^{-1}$, over about $18 \mathrm{~h}$ (DOY 50.85-51.35; Fig. 6). Meteorological and oceanographic conditions were relatively constant during the $\mathrm{B} 1$ transect, with wind speeds ranging from 5.5 to $9.7 \mathrm{~m} \mathrm{~s}^{-1}$, wind direction from 5 to $33^{\circ}$, air temperature of $15.4 \pm 0.8$, and SST of $14.4 \pm 0.5$ (Fig. 7). Atmospheric stability was neutral to stable during this period. A detailed picture of surface ocean DMS levels in and around B1 can be seen from the data collected between DOY 45.65 and DOY 51.35 (Fig. 6). DMS levels exhibit a sharp step change at approximately $44.6^{\circ} \mathrm{S}$. DMS concentrations south of the bloom were less than $5 \mathrm{nM}$. Near the bloom center, levels increased rapidly over a few kilometers from below $10 \mathrm{nM}$ to greater than $15 \mathrm{nM}$. Atmospheric DMS levels were quite stable during the transect, with a mean of $489 \pm 58 \mathrm{ppt}$. The ship's heading (approx. $27^{\circ}$ ) meant that winds blew almost directly onto the bow, with less than $10^{\circ}$ difference for the final $60 \mathrm{~km}$ of the transect back into B1.

Figure 7 depicts seawater DMS levels (green symbols) as the ship steamed into B1 waters. DMS levels $120 \mathrm{~km}$ away from the bloom were below $5 \mathrm{nM}$ and consistently $5-10 \mathrm{nM}$ until the southern perimeter of the bloom $(0 \mathrm{~km})$. DMS levels increased rapidly to $15-20 \mathrm{nM}$ as the ship moved into 


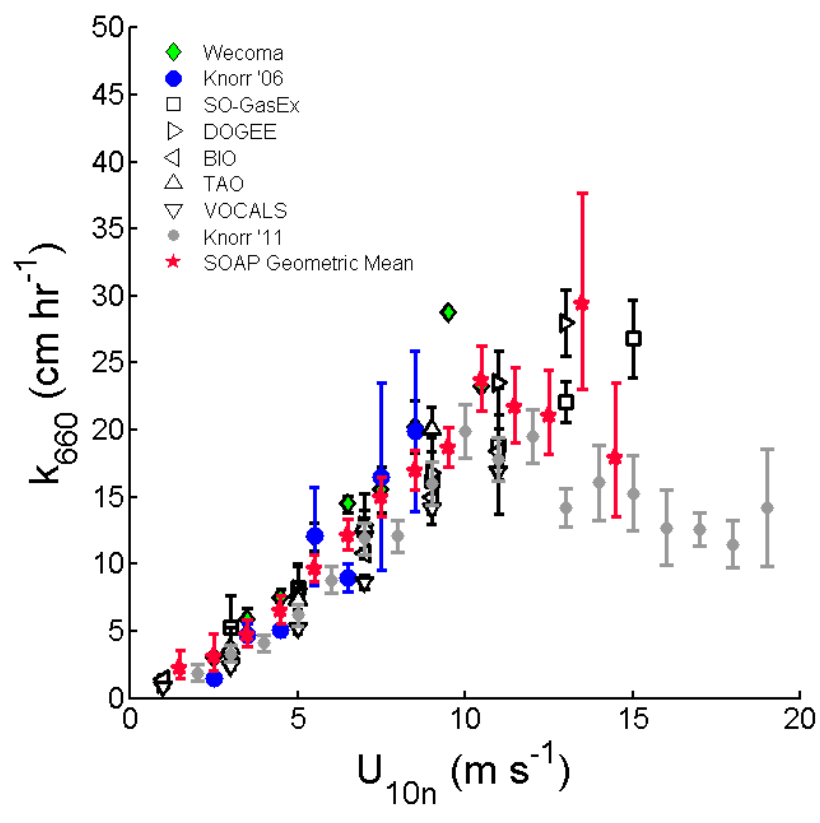

Figure 5. Bin average gas transfer coefficients from this study compared with prior published DMS eddy covariance measurements: Wecoma (Marandino et al., 2007), Knorr '06 (Marandino et al., 2009), SO-GasEx (Yang et al., 2011), DOGEE (Huebert et al., 2010), BIO (Blomquist et al., 2006), TAO (Huebert et al., 2004), VOCALS (Yang et al., 2011) and Knorr'11 (Bell et al., 2013). Geometric mean SOAP $k_{660}$ values were calculated for $1 \mathrm{~m} \mathrm{~s}^{-1} U_{10 n}$ bins (error bars represent $\pm 2 \mathrm{SE}$; minimum data points per inter$\mathrm{val}=6)$.

the bloom. DMS flux divided by the horizontal wind speed is also presented. We assume a relatively linear relationship between $k_{660}$ and $U_{10 n}$ and that fluctuations in $F_{\mathrm{DMS}} / U_{10 n}$ (Fig. 7, blue symbols) are driven primarily by changes in $\Delta C$ (i.e., $\mathrm{DMS}_{\mathrm{sw}}$ ). Spikes in $F_{\mathrm{DMS}} / U_{10 n}$ are evident in $\mathrm{DMS}_{\mathrm{sw}}$ after a consistent distance/time lag. The gas transfer velocities are shown in Fig. 7e during the transect into B1. COARE model output for DMS is plotted as a reference line. Spikes in $k_{660}$ are coincident with sharp changes in $F_{\mathrm{DMS}} / U_{10 n}$ prior to the lagged corresponding change in $\mathrm{DMS}_{\mathrm{sw}}$.

On this transect, the eddy covariance flux footprint was directly ahead of the ship, so a lag would be expected between the $F_{\mathrm{DMS}}$ and $\Delta C$ (i.e., $\mathrm{DMS}_{\mathrm{sw}}$ ). The maximum correlation between $F_{\mathrm{DMS}} / U_{10}$ (using the midpoint of the flux interval) and $\Delta C$ was obtained for a lag of $8 \mathrm{~min}$. This lag represents a distance of $\sim 2.5 \mathrm{~km}$ at $5.1 \mathrm{~m} \mathrm{~s}^{-1}$ ship speed. Applying this lag to the calculation of gas transfer velocity reduced the scatter (Fig. 8). We compared the flux footprint obtained from the lag calculation to a flux footprint calculation using an online version of an analytic dispersion model (http://www.geos.ed.ac.uk/abs/ research/micromet/java/flux.html; Kormann and Meixner, 2001). We ran the model with representative conditions for the SOAP B1 transect: measurement height $=12 \mathrm{~m}$; wind

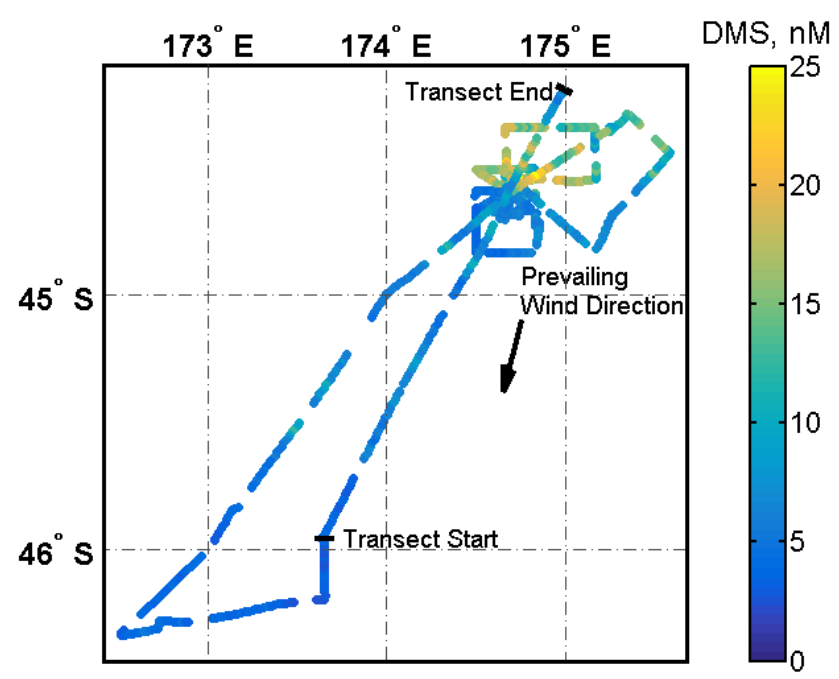

Figure 6. Latitude-longitude map of surface ocean DMS concentrations (nM) in and around B1 waters between DOY 45.65 and 51.35. Start and end points of the transect into B1 are indicated. The arrow indicates the prevailing wind direction along the transect.

speed $=8 \mathrm{~m} \mathrm{~s}^{-1}$; roughness length $=0.02 \mathrm{~m}$ (minimum value available); zero-plane displacement $=0.5 \mathrm{~m}$ (minimum value available); sensible heat flux $=-20 \mathrm{~W} \mathrm{~m}^{-2}$; air temperature $=15^{\circ} \mathrm{C}$. The footprint model predicts a peak relative flux contribution (defined as $90 \%$ of the relative flux) $0.8 \mathrm{~km}$ ahead of the ship, less than half of the distance inferred from the field observations. The calculated footprint is highly sensitive to the input parameters. During the SOAP B1 transect, atmospheric stability was slightly stable but close to neutral $(z / L \sim+0.1)$. Relatively small changes in wind speed $\left( \pm 1 \mathrm{~m} \mathrm{~s}^{-1}\right)$, temperature $\left( \pm 1^{\circ} \mathrm{C}\right)$ or sensible heat flux $\left(+10 \mathrm{~W} \mathrm{~m}^{-2}\right)$ alter the stability such that model predictions of the peak footprint contribution range from 0.3 to $1.9 \mathrm{~km}$. Model runs where measurement height was varied to reflect the limits of ship motion (significant wave height from ECMWF suggests the vertical displacement of the flux inlet was at least $2.5 \mathrm{~m}$ ) gave minimum and maximum peak flux footprint contributions of 0.4 and $2.0 \mathrm{~km}$, respectively.

Despite the sensitivity of the model to the input parameters, these estimates are not as large as the footprint derived from the lag calculation. Flux footprint models make the assumption that the surface source is spatially homogeneous. This was not true during the SOAP B1 transect - the location of the peak contribution to the flux was not the same as the peak in the footprint model. Greater $\mathrm{DMS}_{\mathrm{sw}}$ concentrations at the farthest extent of the flux footprint will cause the flux signal to be dominated by a signal from farther afield than implied by the footprint model. This is the likely explanation for the mismatch between our correlation analysis and the flux footprint model output.

Huebert et al. (2010) addressed surface ocean spatial heterogeneity for their estimates of DMS gas transfer veloc- 


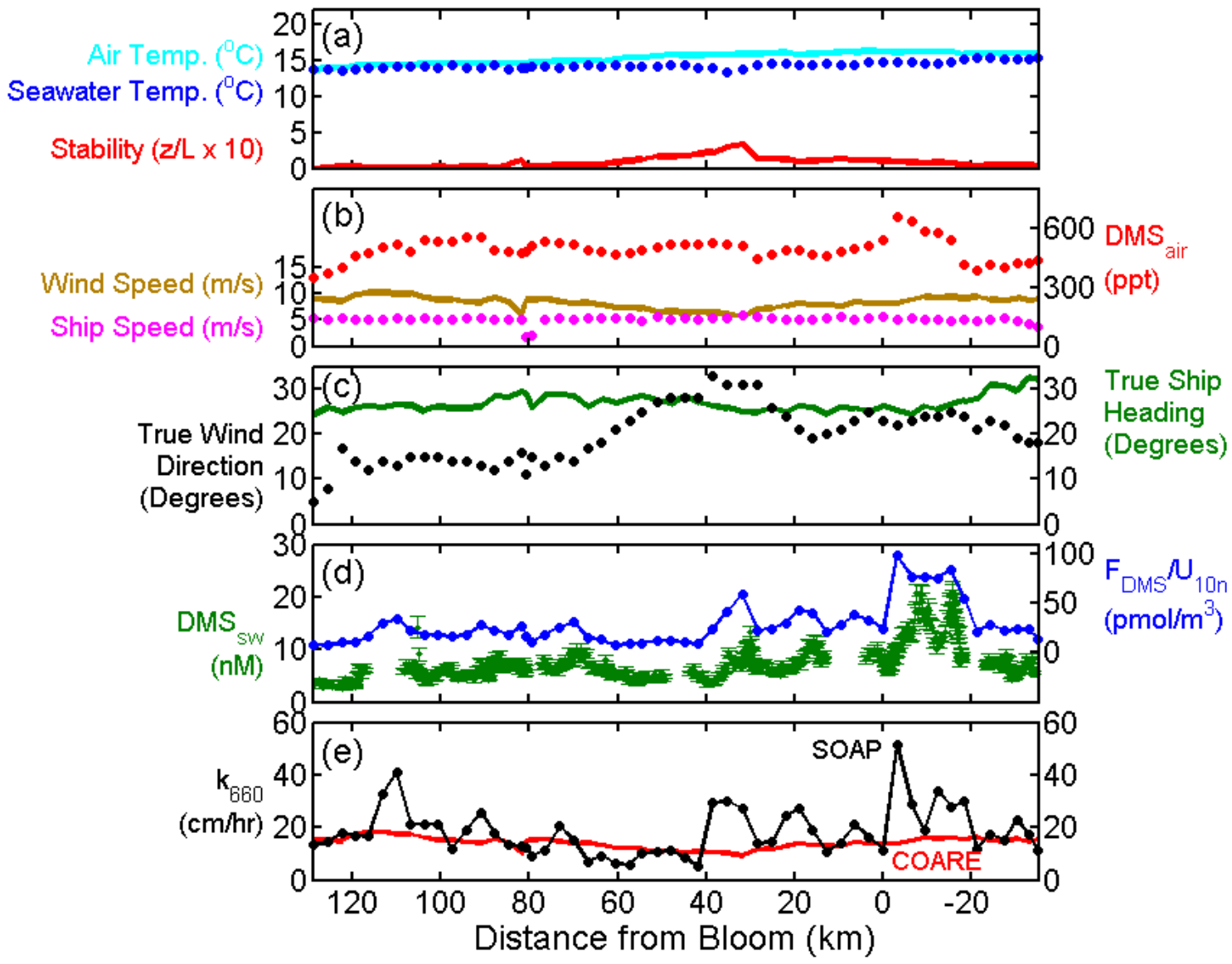

Figure 7. Shipboard measurements during the south-north transect into B1. The data are plotted as a function of distance from the southern perimeter of the bloom. Symbols represent 10 min averages, with the exception of 1 min average seawater DMS concentrations (d). The red line in (e) is the COARE model output for DMS, shown for reference.

ity during the June 2007 Deep Ocean Gas Exchange Experiment (DOGEE) in the North Atlantic. When the hourly $\mathrm{DMS}_{\mathrm{sw}}$ relative standard error of the mean (RSEM) exceeded 0.25 , gas exchange data were not included in their analysis. Removing $k_{660}$ data with high $\mathrm{DMS}_{\mathrm{sw}}$ variability during DOGEE improved the correlation between $k_{660}$ and wind speed. We assessed variability in our high-frequency $\mathrm{DMS}_{\mathrm{sw}}$ data by calculating the forward-looking, running standard deviation (SD) on a $1 \mathrm{~h}$ timescale. The relative standard deviation (RSD) was then calculated by dividing the SD by $\mathrm{DMS}_{\mathrm{sw}}$. Using the RSD would not have been reliable for identifying the outlying $k_{660}$ data during the $\mathrm{B} 1$ transect (Fig. 8a). The scatter in $k_{660}$ vs. $U_{10 n}$ in the entire SOAP data set cannot be reduced on the basis of the associated RSD values (Fig. L in the Supplement).

\section{Conclusions}

The SOAP $k_{660}$ bin average values are in good agreement with previous gas transfer studies using eddy covariance of DMS (Yang et al., 2011; Bell et al., 2013; Marandino et al.,
2007). As noted earlier, these studies provide evidence that interfacial gas transfer is a relatively linear function of wind speed for low to intermediate wind speeds. There is some evidence that the dependence on wind speed weakens at higher wind speeds, both in this study and in the Knorr_11 study (Bell et al., 2013). There is no evidence in any of the DMS eddy covariance data sets that the interfacial (non-bubblemediated) component of gas transfer has a wind speed dependence greater than linear. However, there are still very limited data above $10 \mathrm{~m} \mathrm{~s}^{-1}$, and the high wind speed trends are uncertain.

The scatter in the SOAP data is typical of shipboard eddy covariance flux measurements. This arises from fluctuations in near-surface turbulence and vertical entrainment, vertical shear, ship motion, heterogeneity in seawater DMS and variations in atmospheric DMS due to chemical losses (Blomquist et al., 2010). We note the skewness of the gas transfer velocities in a given wind speed range and use geometric statistics to characterize the central tendency and variance of the data. This skewness is likely driven by the inherent log-normal distribution of seawater DMS levels. We 

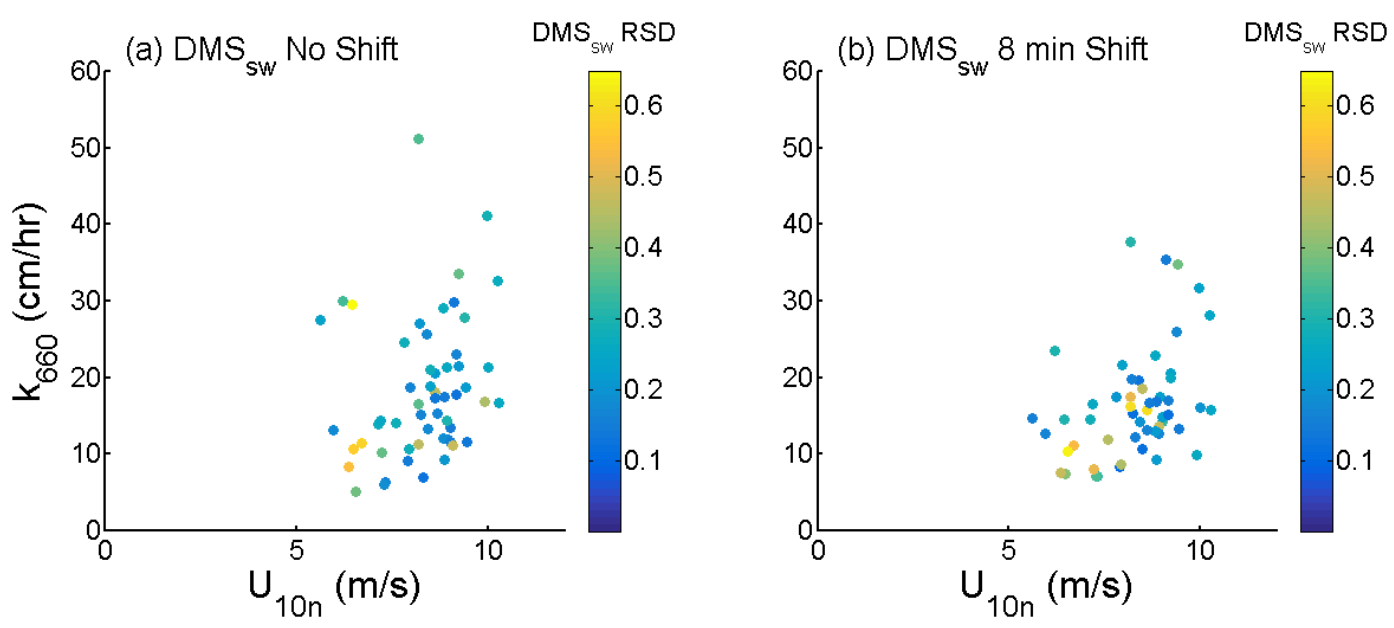

Figure 8. $10 \mathrm{~min}$ average DMS gas transfer coefficients $\left(k_{660}\right)$ vs. mean horizontal wind speed $\left(U_{10 n}\right)$ during the south-north transect into B1 waters. Data are colored by the relative standard deviation (RSD) for corresponding DMS $_{\mathrm{sw}}$ (see text). (a) Gas transfer velocities calculated before adjustment of $\mathrm{DMS}_{\mathrm{sw}}$ to account for decoupling from the flux footprint. (b) $k_{660}$ calculated using seawater DMS shifted by 8 min to account for the lag between measured flux and $\Delta C$ (see text).

propose that spatial heterogeneity in seawater DMS causes decorrelation between the measured seawater DMS and the observed DMS flux, which results in skewness propagating into the calculated transfer coefficients. The data from this study may be particularly influenced by the large differences in seawater DMS values inside and outside the phytoplankton blooms. Similar skewness was observed in data from the North Atlantic Ocean (Bell et al., 2013), and this phenomenon likely affects all DMS eddy covariance studies to some degree. If so, then some transformation of the DMS gas transfer velocities is warranted.

The transect from WP1 into B1 provided a unique opportunity to quantitatively estimate the spatial extent of the eddy covariance flux footprint. The data suggest that the shipboard flux measurements were sensitive to changes in seawater DMS approximately $2.5 \mathrm{~km}$ upwind of the ship, a surprisingly large distance. This transect was conducted under neutral to stable conditions, when one might expect the flux footprint to be relatively large. This result is much greater (twofold or more) than that predicted using an analytic dispersion model (Kormann and Meixner, 2001). The discrepancy between the flux footprint model output and our correlation analysis is probably because the model assumes spatial homogeneity in the $\mathrm{DMS}_{\mathrm{sw}}$ concentrations within the flux footprint. A flux footprint model developed for marine airsea gas flux measurements would be an invaluable tool for the ocean-atmosphere gas exchange research community.

During the SOAP cruise, we saw no obvious evidence of a first-order biological effect on gas transfer coefficients. From this, it could be inferred that surfactants in the dinoflagellate and coccolithophore blooms did not exert a significant effect on water side turbulence. Any modification of the gas transfer velocity vs. wind speed relationship by surfactants or waves during SOAP was masked by other influences upon the variability in gas flux measurements. Minimizing the scatter in gas transfer velocity is critical in order to observe the influence of non-wind-speed processes and to draw firm conclusions about their impact upon air-sea gas transfer. The challenge for the gas exchange community is that heterogeneity in seawater DMS concentrations is linked to phytoplankton growth, which likely also determines surfactant effects upon the gas transfer velocity.

\section{The Supplement related to this article is available online at doi:10.5194/acp-15-1783-2015-supplement.}

Acknowledgements. The authors thank the New Zealand National Institute of Water and Atmospheric Research (NIWA) and the Captain and crew of the R/V Tangaroa for their assistance in carrying out this cruise. We also thank Cyril McCormick (UCI Instrument Development Facility) for essential technical support and Mike Harvey for logistical assistance before, during and after the SOAP cruise. Thanks to Mark Gall (NIWA) for processing the underway fluorescence data to provide calibrated chlorophyll $a$ values. We are grateful to Brian Ward and Kai Christensen for providing ECMWF-derived significant wave height data and to Mingxi Yang for insightful discussion during data analysis. This research was supported by the NSF Atmospheric Chemistry Program (grant nos. 08568, 0851472, 0851407 and 1143709) as a contribution to US SOLAS. The NIWA Atmosphere Centre supported the Ocean-Atmosphere Programme as a contribution to NZ SOLAS. We are grateful to both reviewers for their considered and constructive comments.

Edited by: P. Quinn 


\section{References}

Bariteau, L., Helmig, D., Fairall, C. W., Hare, J. E., Hueber, J., and Lang, E. K.: Determination of oceanic ozone deposition by shipborne eddy covariance flux measurements, Atmos. Meas. Tech., 3, 441-455, doi:10.5194/amt-3-441-2010, 2010

Bell, T. G., De Bruyn, W., Miller, S. D., Ward, B., Christensen, K. H., and Saltzman, E. S.: Air-sea dimethylsulfide (DMS) gas transfer in the North Atlantic: evidence for limited interfacial gas exchange at high wind speed, Atmos. Chem. Phys., 13, 1107311087, doi:10.5194/acp-13-11073-2013, 2013.

Blomquist, B. W., Fairall, C. W., Huebert, B. J., Kieber, D. J., and Westby, G. R.: DMS sea-air transfer velocity: Direct measurements by eddy covariance and parameterization based on the NOAA/COARE gas transfer model, Geophys. Res. Lett., 33, L07601, doi:10.1029/2006g1025735, 2006.

Blomquist, B. W., Huebert, B. J., Fairall, C. W., and Faloona, I. C.: Determining the sea-air flux of dimethylsulfide by eddy correlation using mass spectrometry, Atmos. Meas. Tech., 3, 1-20, doi:10.5194/amt-3-1-2010, 2010.

Blomquist, B. W., Fairall, C. W., Huebert, B. J., and Wilson, S. T.: Direct measurement of the oceanic carbon monoxide flux by eddy correlation, Atmos. Meas. Tech., 5, 3069-3075, doi:10.5194/amt-5-3069-2012, 2012.

Coburn, S., Ortega, I., Thalman, R., Blomquist, B., Fairall, C. W., and Volkamer, R.: Measurements of diurnal variations and eddy covariance (EC) fluxes of glyoxal in the tropical marine boundary layer: description of the Fast LED-CE-DOAS instrument, Atmos. Meas. Tech., 7, 3579-3595, doi:10.5194/amt-7-3579-2014, 2014.

Dacey, J. W. H., Wakeham, S. G., and Howes, B. L.: Henry's law constants for dimethylsulfide in fresh water and seawater, Geophys. Res. Lett., 11, 991-994, 1984.

Donelan, M. A., Haus, B. K., Plant, W. J., and Troianowski, O.: Modulation of short wind waves by long waves, J. Geophys. Res.-Ocean., 115, C10003, doi:10.1029/2009jc005794, 2010.

Edson, J. B., Hinton, A. A., Prada, K. E., Hare, J. E., and Fairall, C. W.: Direct covariance flux estimates from mobile platforms at sea, J. Atmos. Ocean. Tech., 15, 547-562, doi:10.1175/15200426(1998)015<0547:DCFEFM>2.0.CO;2, 1998.

Elliott, S.: Dependence of DMS global sea-air flux distribution on transfer velocity and concentration field type, J. Geophys. Res., 114, G02001, doi:10.1029/2008JG000710, 2009.

Fairall, C. W., Yang, M., Bariteau, L., Edson, J. B., Helmig, D., McGillis, W., Pezoa, S., Hare, J. E., Huebert, B., and Blomquist, B.: Implementation of the Coupled OceanAtmosphere Response Experiment flux algorithm with $\mathrm{CO}_{2}$, dimethyl sulfide, and O3, J. Geophys. Res.-Oceans, 116, C00F09, doi:10.1029/2010jc006884, 2011.

Frew, N. M., Goldman, J. C., Dennett, M. R., and Johnson, A. S.: Impact of phytoplankton-generated surfactants on airsea gas-exchange, J. Geophys. Res.-Oceans, 95, 3337-3352, doi:10.1029/Jc095ic03p03337, 1990.

Ho, D. T., Wanninkhof, R., Schlosser, P., Ullman, D. S., Hebert, D., and Sullivan, K. F.: Toward a universal relationship between wind speed and gas exchange: Gas transfer velocities measured with ${ }^{3} \mathrm{He}_{\mathrm{S}} \mathrm{SF}_{6}$ during the Southern Ocean Gas Exchange Experiment, J. Geophys. Res., 116, C00F04, doi:10.1029/2010jc006854, 2011.
Huebert, B. J., Blomquist, B. W., Hare, J. E., Fairall, C. W., Johnson, J. E., and Bates, T. S.: Measurement of the sea-air DMS flux and transfer velocity using eddy correlation, Geophys. Res. Lett., 31, L23113, doi:10.1029/2004g1021567, 2004.

Huebert, B. J., Blomquist, B. W., Yang, M. X., Archer, S. D., Nightingale, P. D., Yelland, M. J., Stephens, J., Pascal, R. W., and Moat, B. I.: Linearity of DMS transfer coefficient with both friction velocity and wind speed in the moderate wind speed range, Geophys. Res. Lett., 37, L01605, doi:10.1029/2009g1041203, 2010.

Kim, M. J., Farmer, D. K., and Bertram, T. H.: A controlling role for the air-sea interface in the chemical processing of reactive nitrogen in the coastal marine boundary layer, P. Natl. Acad. Sci. USA, 111, 3943-3948, doi:10.1073/pnas.1318694111, 2014.

Kormann, R. and Meixner, F. X.: An analytical footprint model for non-neutral stratification, Bound.-Lay. Meteorol., 99, 207-224, doi:10.1023/a:1018991015119, 2001.

Lana, A., Bell, T. G., Simó, R., Vallina, S. M., Ballabrera-Poy, J., Kettle, A. J., Dachs, J., Bopp, L., Saltzman, E. S., Stefels, J., Johnson, J. E., and Liss, P. S.: An updated climatology of surface dimethylsulfide concentrations and emission fluxes in the global ocean, Global Biogeochem. Cy., 25, GB1004, doi:10.1029/2010gb003850, 2011.

Liss, P. S. and Slater, P. G.: Flux of gases across the air-sea interface, Nature, 247, 181-184, 1974.

Marandino, C. A., De Bruyn, W. J., Miller, S. D., Prather, M. J., and Saltzman, E. S.: Oceanic uptake and the global atmospheric acetone budget, Geophys. Res. Lett., 32, L15806, doi:10.1029/2005g1023285, 2005.

Marandino, C. A., De Bruyn, W. J., Miller, S. D., and Saltzman, E. S.: Eddy correlation measurements of the air/sea flux of dimethylsulfide over the North Pacific Ocean, J. Geophys. Res.Atmos., 112, D03301, doi:10.1029/2006jd007293, 2007.

Marandino, C. A., De Bruyn, W. J., Miller, S. D., and Saltzman, E. S.: DMS air/sea flux and gas transfer coefficients from the North Atlantic summertime coccolithophore bloom, Geophys. Res. Lett., 35, L23812, doi:10.1029/2008g1036370, 2008.

Marandino, C. A., De Bruyn, W. J., Miller, S. D., and Saltzman, E. S.: Open ocean DMS air/sea fluxes over the eastern South Pacific Ocean, Atmos. Chem. Phys., 9, 345-356, doi:10.5194/acp9-345-2009, 2009.

McGillis, W. R., Edson, J. B., Hare, J. E., and Fairall, C. W.: Direct covariance air-sea $\mathrm{CO}_{2}$ fluxes, J. Geophys. Res.-Oceans, 106, 16729-16745, 2001.

Miller, S. D., Hristov, T. S., Edson, J. B., and Friehe, C. A.: Platform motion effects on measurements of turbulence and air-sea exchange over the open ocean, J. Atmos. Ocean. Tech., 25, 1683 1694, doi:10.1175/2008jtecho547.1, 2008.

Miller, S. D., Marandino, C., and Saltzman, E. S.: Ship-based measurement of air-sea $\mathrm{CO}_{2}$ exchange by eddy covariance, J. Geophys. Res.-Atmos., 115, D02304, doi:10.1029/2009jd012193, 2010.

Nightingale, P. D., Malin, G., Law, C. S., Watson, A. J., Liss, P. S., Liddicoat, M. I., Boutin, J., and Upstill-Goddard, R. C.: In situ evaluation of air-sea gas exchange parameterizations using novel conservative and volatile tracers, Global Biogeochem. Cy., 14, 373-387, 2000.

Popinet, S., Smith, M., and Stevens, C.: Experimental and numerical study of the turbulence characteristics of airflow around 
a research vessel, J. Atmos. Ocean. Tech., 21, 1575-1589, doi:10.1175/1520-0426(2004)021<1575:Eansot>2.0.Co;2, 2004.

Sabine, C. L., Feely, R. A., Gruber, N., Key, R. M., Lee, K., Bullister, J. L., Wanninkhof, R., Wong, C. S., Wallace, D. W. R., Tilbrook, B., Millero, F. J., Peng, T. H., Kozyr, A., Ono, T., and Rios, A. F.: The oceanic sink for anthropogenic $\mathrm{CO}_{2}$, Science, 305, 5682, 367-371, doi:10.1126/science.1097403, 2004.

Salter, M. E., Upstill-Goddard, R. C., Nightingale, P. D., Archer, S. D., Blomquist, B., Ho, D. T., Huebert, B., Schlosser, P., and Yang, M.: Impact of an artificial surfactant release on air-sea gas fluxes during Deep Ocean Gas Exchange Experiment II, J. Geophys. Res.-Oceans, 116, C11016, doi:10.1029/2011jc007023, 2011.

Saltzman, E. S., King, D. B., Holmen, K., and Leck, C.: Experimental determination of the diffusion coefficient of dimethylsulfide in water, J. Geophys. Res.-Oceans, 98, 16481-16486, 1993.

Saltzman, E. S., De Bruyn, W. J., Lawler, M. J., Marandino, C. A., and McCormick, C. A.: A chemical ionization mass spectrometer for continuous underway shipboard analysis of dimethylsulfide in near-surface seawater, Ocean Sci., 5, 537-546, doi:10.5194/os-5-537-2009, 2009.

Smith, M. J., Ho, D. T., Law, C. S., McGregor, J., Popinet, S., and Schlosser, P.: Uncertainties in gas exchange parameterization during the SAGE dual-tracer experiment, Deep-Sea Res. Part II-Top. Stud. Oceanogr., 58, 869-881, doi:10.1016/j.dsr2.2010.10.025, 2011.
Soloviev, A. V.: Coupled renewal model of ocean viscous sublayer, thermal skin effect and interfacial gas transfer velocity, J. Marine Syst., 66, 19-27, doi:10.1016/j.jmarsys.2006.03.024, 2007.

Soloviev, A. V., Donelan, M., Graber, H., Haus, B., and Schlüssel, P.: An approach to estimation of near-surface turbulence and $\mathrm{CO}_{2}$ transfer velocity from remote sensing data, J. Marine Syst., 66, 182-194, doi:10.1016/j.jmarsys.2006.03.023, 2007.

Sweeney, C., Gloor, E., Jacobson, A. R., Key, R. M., McKinley, G., Sarmiento, J. L., and Wanninkhof, R.: Constraining global air-sea gas exchange for $\mathrm{CO}_{2}$ with recent bomb ${ }^{14} \mathrm{C}$ measurements, Global Biogeochem. Cy., 21, GB2015, doi:10.1029/2006gb002784, 2007.

Woolf, D. K.: Bubbles and their role in gas exchange, in: The Sea Surface and Global Change, edited by: Liss, P. S., and Duce, R. A., Cambridge University Press, Cambridge, 173-205, 1997.

Yang, M., Blomquist, B. W., and Huebert, B. J.: Constraining the concentration of the hydroxyl radical in a stratocumulus-topped marine boundary layer from sea-to-air eddy covariance flux measurements of dimethylsulfide, Atmos. Chem. Phys., 9, 92259236, doi:10.5194/acp-9-9225-2009, 2009.

Yang, M., Blomquist, B. W., Fairall, C. W., Archer, S. D., and Huebert, B. J.: Air-sea exchange of dimethylsulfide in the Southern Ocean: Measurements from SO GasEx compared to temperate and tropical regions, J. Geophys. Res.-Oceans, 116, C00F05, doi:10.1029/2010jc006526, 2011.

Yang, M., Beale, R., Smyth, T., and Blomquist, B.: Measurements of OVOC fluxes by eddy covariance using a proton-transferreaction mass spectrometer - method development at a coastal site, Atmos. Chem. Phys., 13, 6165-6184, doi:10.5194/acp-136165-2013, 2013. 